\title{
Phenotypic polymorphism, pomological and chemical characteristics of some local varieties of fig trees (Ficus carica L.) grown in Eastern Morocco
}

\author{
Aziz Tikent ${ }^{1}$, Ahmed Marhri $^{1}$, Atika Mihamou ${ }^{1}$, Nargis Sahib ${ }^{1}$, Hana Serghini-Caid ${ }^{1}$, Ahmed Elamrani $^{1}$, Malika \\ Abid $^{1}$, and Mohamed Addi ${ }^{1}$ \\ ${ }^{1}$ Laboratoire d'Amélioration des Productions agricoles, Biotechnologie \& Environnement (LAPABE), Faculté des Sciences, \\ Université Mohammed Premier, BP : 717, 60000, Oujda, Morocco
}

\begin{abstract}
The fig tree (Ficus carica L.) is one of the earliest fruit trees cultivated in Morocco, especially in the north-eastern region; which is growing inextricably linked to our social and cultural heritage. This study concerns morpho-pomological and chemical parameters of five local fig varieties, namely: Aounk Hmam "AH", Chetoui "CH", Bounacer "BN", Ghoudane "GH", and Malha "MA". Significant differences were observed among the studied fig cultivars for some of the parameters investigated. In particular, the average fruit weight that ranged from $29.72 \mathrm{~g}$ to $58 \mathrm{~g}$ for MA and AH respectively. At the ripening stage, fruits "MA" show the best skin cracks, while fruits "AH" are distinguished by their ease of peeling.In terms of titratable acidity, "AH" has the lowest value, while "CH" has the highest level. For the sweetest and tastiest variety of figs, Brix readings (expressed as total soluble solids content) registred range between 27 - 35\% respectively for the MA and GH . According to the results of the parameters evaluated, particularly the acidity and the Brix index, the best varieties worthy of consideration from an agricultural and industrial point of view are "AH" and "CH" cultivars.
\end{abstract}

\section{Introduction}

The common fig (Ficus carica L., $2 \mathrm{n}=26$ ) belongs to the family Moraceae with more than 800 species[1], native to western Asia and the eastern part of the Mediterranean regions[2,3]. It was one of the first Mediterranean fruit species to be domesticate[4,5].The fig and olive trees are among the oldest domesticated trees in Morocco's northern region (Rif) [6]. Several studies on the fig tree's characterization have been conducted in Morocco. In the northern region of Morocco (Rif), Hmimsa et al [7] conducted a vernacular classification of fig varieties based on biological, agronomic, and use characteristics. The research revealed a high level of diversity among local fig varieties. The high level of intraspecific diversity, as well as the complexity of the naming system and classification system for fig varieties, is associated with high sociocultural and economic values. El Hajjami's [8] inventory of Moroccan local varieties of fig (Ficus carica L.) in four main production sites, (Chefchaouen, El Jadida, Ouezzane, and Taounate provinces) revealed the presence of 43 varieties. The principal component analysis (PCA) and agglomerative hierarchical clustering (AHC) have revealed similarities between some varieties. Hssaini et al [9] collected and analyzed phenotypic variation in fig accessions grown in three northern Moroccan regions (Taounate, Ouazzane, and Meknes). Based on pomological traits, they discovered three distinct groups with a total inertia of $90.92 \%$. In Morocco, Figs are also a valuable social resource. Figs are popular as gifts (fresh or dried) for family and friends, especially during religious events. The Ministry of Agriculture, Maritime Fisheries, Rural Development, Water and Forests has launched a project to plant 100 hectares of fig trees and build a drying unit in the rural municipality of Aghbal in the province of Berkane over the period 2019-2020 as part of the Green Morocco Plan. The project's objectives include the enhancement and development of the fig sector, as well as the improvement of the fig sector's productivity. The farmers involved in this project led by the cooperative "Gharmawne" will benefit from support equipment, training and supervision. In partnership with the municipality and other agricultural creators, this cooperative organizes each year the Aghbal festival of figs, a socio-economic event that aims to bring together consumers and producers of figs in eastern morocco. This event is held every year during the last weekend of August. The festival is an opportunity to promote the commercialization of figs and fig's derivative products, to encourage the innovation of small producers in this sector, and to show the natural and cultural assets of this region. The local fig

${ }^{*}$ Corresponding author:tikent.aziz@ump.ac.ma 
germplasm has not been subjected to intensive plant selection programs; as a result many fig populations and ecosystems had a great genetic diversity, which must to be fully exploited by its identification and classification[9].The fig has a wide geographical distribution in the country and is well-known for its high commercial value and best fruit flavor for fresh consumption. When compared to many other fig cultivars, the local fruits are known to be very high in sugars, the most important criterion of quality in figs. The purpose of this study is to assess the impact of different agro-ecological zones on the fruit quality of local fig varieties. Besides, this work aims to identify the morphological characteristics of local fig varieties and estimate the quality of their fruit, respectively, according to the morpho-pomological traits based on the IPGRI and CIHEAM descriptors $[10,11]$ and to the Aksoy's fig fruits quality descriptors[12], in order to conserve the fig germplasm and preserve this species from genetic erosion.

\section{Materials and methods 2.1 Materials sampling}

The sampling region (made up of 7 provinces and a prefecture) located in the northeast of the country (fig1), it covers an area of $90.130 \mathrm{~km}^{2}$, accounting for or $12.7 \%$ of the country's total land area [13].

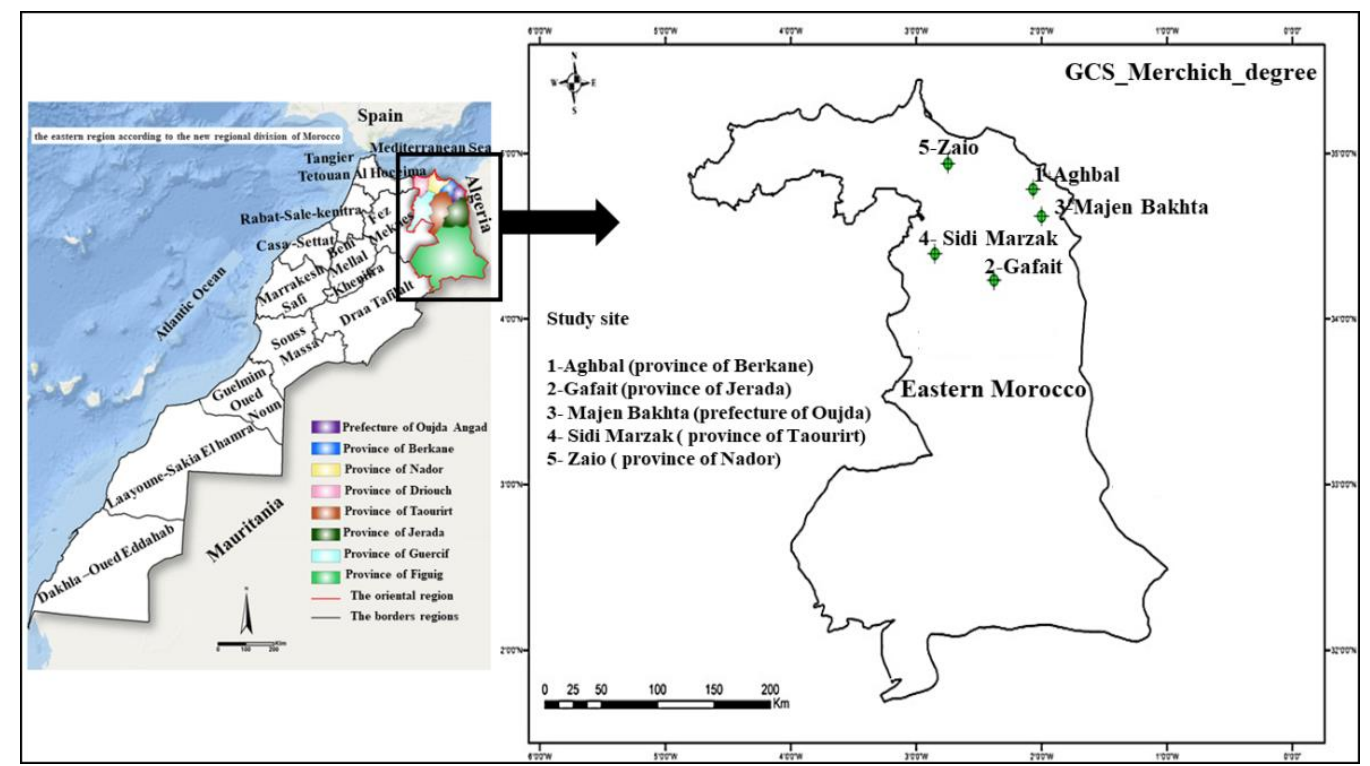

Fig1. Geographical location of the study in eastern Morocco. The area is delimited, to the north by the Mediterranean Sea, and to the south by the arid region of Daraa-Tafilalete. The climate of this region is Mediterranean in the north, with rare precipitation, often in the form of strong thunderstorms and continental in the south, sensitive to Saharan factors, with cold in winter and heat in summer, low rainfall generally poorly distributed in time and space[13].

Table1. Short name (Code) with important features of the five fig cultivars studied

\begin{tabular}{|l|l|l|l|l|l|}
\hline $\mathrm{N}$ & Fig cultivars & Code & Figs category & Autumn fig skin color & utilisation \\
\hline 1 & Aounk Hmam & AH & unifer figs & Purple spotted in green & Fresh \\
\hline 2 & Bounacer & BN & bifer figs & Black more than purple & Fresh \\
\hline 3 & Chetoui & CH & unifer figs & Green spotted in purple & Fresh/Dried \\
\hline 4 & Ghoudane & GH & bifer figs & Black & Fresh/Dried \\
\hline 5 & Malha & MA & unifer figs & Green & Fresh \\
\hline
\end{tabular}

The identification of trees (Table 1) was made with the local vernacular name given by farmer to crop and cultivar, and they were selected for their widespread distribution and their commercial value in this region. Prospection and sampling were carried out on traditional orchards of farmers (adult trees of roughly the same age " ten years") at different locations in eastern Morocco (fig 1), in the early of February for the apical buds and during the period (June, July ,August and September) for the fruits and leaves. At the level of three different zones in each site, samples of 150 fresh fruits (ten fruits per plant and three plants per cultivars in each zone for two successive years 2019-2020) ripe and disease free were chosen, selected (the most basal on shoot) and harvested. According to the description instructions, the same sampling approach was used for leaves and apical buds. 


\subsection{Phenotypic and pomological Study}

A digital scale was used to take the fruit weight measurements. (KERN PCB 2000-1 Max $2000 \mathrm{~g} \mathrm{~d}=0.1 \mathrm{~g}$ ), the length and width of the fruit, the neck and the fruit stalk, the ostiole width ,the internal fruit pulp thickness carried out with a digital caliper PAQUIMETRO DIGITAL INOX 0-150MM), the index = fig width/fig length ( Oblong < 0. 9; globose 0. 9-1.1; Oblate > 1.1) and the ease of peeling (easy, medium, difficult) and lack of skin cracks (without cracks, longitudinal, Cracked skin) are determined. The leaf dimensions (length and width) were measured with a graduated ruler, while the thickness of the leaf stalk carried out with a digital caliper (in $\mathrm{mm}$ ).As well as the terminal bud length and width were carried out with a digital caliper (in $\mathrm{mm}$ ).

\subsection{Chemical analysis}

The chemical analyzes were carried out in triplicate and focused on the acidity and the Brix as a metric of fruit maturity parameters. The titratable acidity (expressed in \% of citric acid) by titrating fig juice with $0.1 \mathrm{M} \mathrm{NaOH}$ to $\mathrm{pH} 8.1$ in the presence of a colored indicator according to the AFNOR method (NF V O5-101, 1970). The Brix index indicates the total content of all sugars as the soluble solids in the fruit. Brix readings were done using digital refractometer (HANNA NUMERIQUE HI 96801 - ECHELLE 0-85\% BRIX).

\subsection{Statistical analysis}

The data obtained was subjected to statistical analysis using IBM SPSS Statistics V21.0 software for descriptive statistics and also for analysis of variance by comparing average of characteristics studied using post hoc testing (Tukey's test) at the 5\% threshold, graphs produced by the GraphPad Prism 8 software. The quality of the figs was assessed using the weighted ranked method by Aksoy [12], based on nine pomological characters.

\section{Results and discussions}

The morphological characterization of the figs was carried out on plant material available at the sampling site and therefore does not take into account the environmental component. Thus, the ease of peeling as well as the presence of skin cracks seems to be positive quality factors for figs intended for consumption in the fresh state. On the other hand, the absence of cracks would be a positive parameter allowing better preservation of dried figs. In addition, we note that this type of figs without skin cracks is intended both for consumption in the fresh state as for the production of dried figs. According to this study, AH had the best quality in terms of peelability while MA had the best quality in terms of skin cracking (Table 2).

Table2.Study results of two important parameter used to determine figs quality by Aksoy ranked method[12]

\begin{tabular}{|l|l|l|}
\hline Cultivar & Ease of peeling & Skin cracks \\
\hline Aounk Hmam $(\mathrm{AH})$ & Easy & longitudinal \\
\hline Bounacer $(\mathrm{BN})$ & Medium & longitudinal \\
\hline Chetoui $(\mathrm{CH})$ & Medium & cracked skin \\
\hline Ghoudane $(\mathrm{GH})$ & Medium & longitudinal \\
\hline Malha $(\mathrm{MA})$ & Medium & without cracks \\
\hline
\end{tabular}

The susceptibility for skin cracks is favored by low temperatures associated with high humidity during the fig ripening and especially common in genotypes with a thin epidermis[14]. Varieties that have a too long maturity are more vulnerable to the problem of skin cracks; they should not be grown in early and rainy autumn areas. When the fruits are ripening, fig cracking begins at the ostiole and is exacerbated by low temperatures and/or an increase in relative humidity[15].

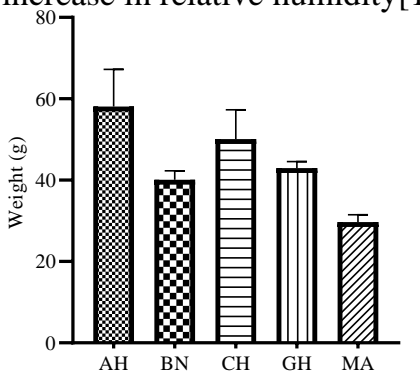

Fig2.Figs weight average

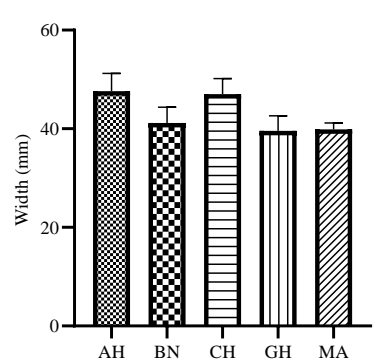

Fig3.Figs width average

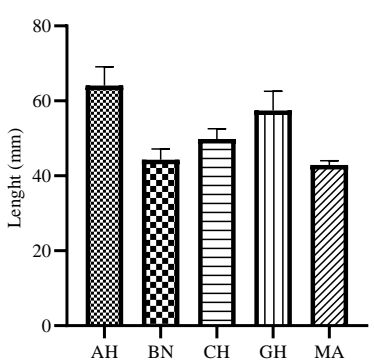

Fig4.Figs length average 
The results show that fig weight (Fig 2) is high in $\mathrm{AH}(58.09 \pm 9.129 \mathrm{~g})$ and $\mathrm{CH}(50.12 \pm 7.209 \mathrm{~g})$ varieties and medium for $\mathrm{GH}(42.94 \pm 1.627 \mathrm{~g})$ and $\mathrm{BN}(40.09 \pm 2.182 \mathrm{~g})$, while MA recorded the lowest weight $(29.72 \pm$ $1.767 \mathrm{~g})$. The figs weight gives extremely attractive pricing for producers and traders in the market, for this purpose $\mathrm{AH}$; $\mathrm{CH}$ and $\mathrm{GH}$ will certainly have the best chances of being appreciated by consumers. According to the results obtained concerning fig width (Fig 3), fig length (Fig 4) and their comparisons with those of the descriptor, we found that the width oscillates between small [28-38 mm]or medium [38-49 mm] at MA (39.88 \pm $1.278 \mathrm{~mm}), \mathrm{GH}(39.56 \pm 3.073 \mathrm{~mm})$ and $\mathrm{BN}(41.16 \pm 3.202 \mathrm{~mm})$, for $\mathrm{CH}(47.03 \pm 3.140 \mathrm{~mm})$ and $\mathrm{AH}(47.63$ $\pm 3.575 \mathrm{~mm})$ it's between medium or large [50-60 mm]. The length is long [54-75 mm] for AH $(64.07 \pm 5.033$ $\mathrm{mm})$, and between medium [29-54 mm] and long for $\mathrm{GH}(57.44 \pm 5.106 \mathrm{~mm})$, and medium for $\mathrm{CH}(49.86 \pm$ $2.728 \mathrm{~mm}), \mathrm{BN}(44.32 \pm 2.856 \mathrm{~mm})$ and MA $(42.88 \pm 1.151 \mathrm{~mm})$.

The Shape fruit changes depending to the stage of maturity and cultural maintenance [16], or because of environmental conditions and genotypic effect [17].In the fresh fig sector, shape or index is particularly important. According to the findings of this study (Fig 5), the oblong form (I < 0.9) is represented in $\mathrm{GH}(0.694 \pm 0.080)$ and $\mathrm{AH}(0.745 \pm 0.049)$, whereas the globose shape $(\mathrm{I}=0.9-1.1)$ characterizes BN $(0.928 \pm$ $0.031)$ and MA $(0.930 \pm 0.022)$ and $\mathrm{CH}(0.943 \pm 0.044)$ varieties, which is suitable for commerce domain due to its appealing appearance and convenience of presentation.

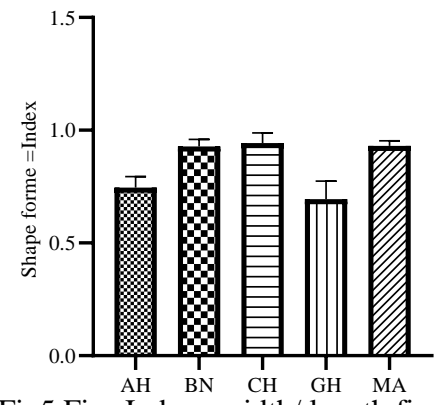

Fig5.Figs Index = width/ length fig average

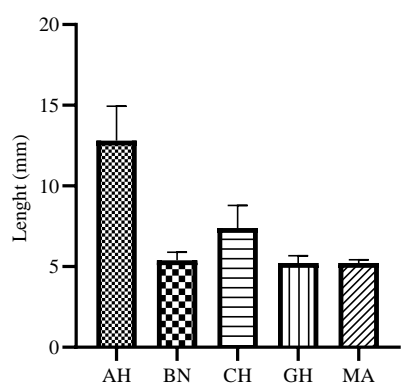

Fig6.Neck length average

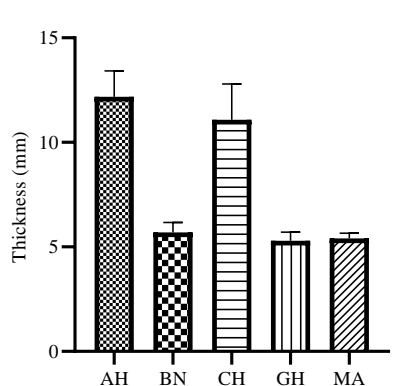

Fig7.Neck thickness average

Furthermore, $\mathrm{AH}(12.81 \pm 2.121 \mathrm{~mm})$ variety has the longest neck followed by $\mathrm{CH}, \mathrm{BN}, \mathrm{MA}$ and $\mathrm{GH}(5.218 \pm$ $0.456 \mathrm{~mm}$ ) in that order (Fig 6). The same results have been observed in terms of fruit's neck thickness. The thickest neck) (Fig 7) belongs to the AH (12.18 $\pm 1.244 \mathrm{~mm}$ ) variety, followed by CH, BN, MA, and GH (5.408 $\pm 0.252 \mathrm{~mm}$ ). It should be noted that for the neck length and the neck thickness BN, GH and MA are very similar. The fig farmers also considered that increasing these two characteristics would improve the freshness of the fig. Moreover, results show that AH $(7.344 \pm 3.287 \mathrm{~mm})$, MA $(8.407 \pm 0.489 \mathrm{~mm})$ and $\mathrm{CH}$ varieties have the longest fruit stalk (Fig 8) compared to BN and GH (4.905 $\pm 0.407 \mathrm{~mm})$. In addition, $\mathrm{AH}(6.557 \pm 0.728 \mathrm{~mm})$, $\mathrm{BN}$, and $\mathrm{CH}$ cultivars have thicker fruit stalks than $\mathrm{GH}$ and MA $(5.106 \pm 0.363 \mathrm{~mm})$ varieties (Fig 9).

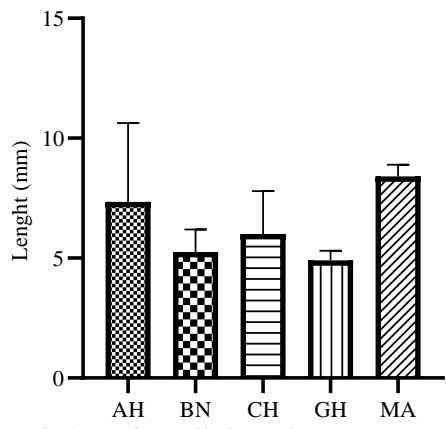

Fig8.Fruit stalk length average

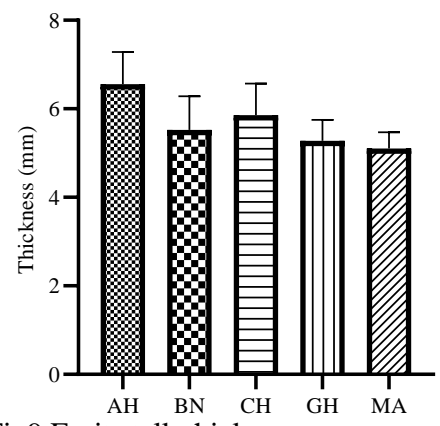

Fig9.Fruit stalk thickness average

Short necks, unlike long stalks, are considered as an undesirable characteristic by arborists because they make harvesting difficult and destructive to the fruit. Varieties with short necks, such as MA, may not be of interest to growers because they are difficult to harvest, whereas varieties with a long neck and stalk, such as $\mathrm{AH}$, are preferable for their ease of harvest.

Results have shown that $\mathrm{AH}(6.887 \pm 1.10 \mathrm{~mm})$ figs have the greatest ostiole width (Fig 10) followed by $\mathrm{CH}$, $\mathrm{GH}, \mathrm{BN}$ and MA $(3.788 \pm 0.24 \mathrm{~mm})$ in that order. The largest pulp width (Fig 11) is seen in AH figs $(43.59 \pm$ $3.528 \mathrm{~mm})$, followed by $\mathrm{CH}, \mathrm{GH}, \mathrm{BN}$, and MA figs $(36.84 \pm 1.293 \mathrm{~mm})$. A large ostiole will facilitate the entry and flight of blastophagous as well as pesticides and pathogens, which make varieties with this character unsuitable for the fig industry and storage [18]. The thickness of the internal pulp is a determining pomological character in the fruit quality and their use. 


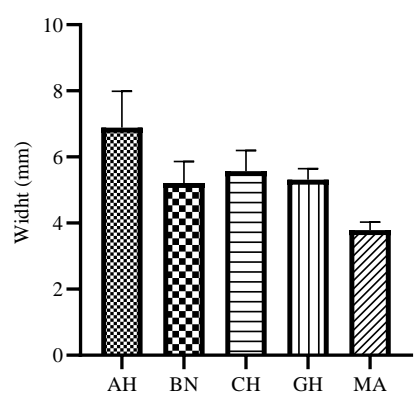

Fig10.Ostiole width average

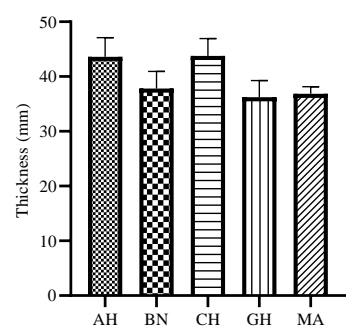

Fig11.Pulp thickness average

There was a lot of heterogeneity amongst the cultivars based on the fruit fig pomological qualities evaluation (Table3), with few exceptions in the following characteristics : width between AH/CH and GH/MA, Fig width/Fig length regarding $\mathrm{BN} ; \mathrm{CH}$ and $\mathrm{MA}$ between them, Ostiole width between BN/GH and $\mathrm{CH} / \mathrm{GH}, \mathrm{Neck}$ length regarding BN;GH and MA between them, Neck thickness regarding BN;GH and MA between them, Stalk length between BN/GH, Stalk thickness between GH/ MA, Pulp thickness between AH/ CH and BN/MA also between GH/ MA.

Table3. Ordinary one-way ANOVA of pomological fig characters $(n=150)$ averages

\begin{tabular}{|c|c|c|c|c|c|c|c|c|c|c|}
\hline $\begin{array}{l}\text { Tukey's multiple } \\
\text { comparisons test }\end{array}$ & $\begin{array}{c}\text { F.W } \\
(\mathrm{g})\end{array}$ & $\begin{array}{l}\text { F.Wi } \\
(\mathrm{mm})\end{array}$ & $\begin{array}{l}\text { F.L } \\
(\mathrm{mm})\end{array}$ & $\begin{array}{l}\mathrm{Wi} / \mathrm{L} \\
\text { Index }\end{array}$ & $\begin{array}{l}\text { O.W } \\
(\mathrm{mm})\end{array}$ & $\begin{array}{l}\text { N.L } \\
(\mathrm{mm})\end{array}$ & $\begin{array}{l}\text { N.T } \\
(\mathrm{mm})\end{array}$ & $\begin{array}{c}\text { S.L } \\
(\mathrm{mm})\end{array}$ & $\begin{array}{l}\text { S.T } \\
(\mathrm{mm})\end{array}$ & $\begin{array}{l}\text { P.T } \\
(\mathrm{mm})\end{array}$ \\
\hline $\mathrm{AH}$ vs $\mathrm{BN}$ & ****** & ***** & ***** & ***** & ***** & $* * * *$ & $* * * *$ & $* * * *$ & ***** & $* * * *$ \\
\hline & 18.00 & 6.472 & 19.75 & -0.1831 & 1.678 & 7.414 & 6.485 & 2.092 & 1.036 & 5.803 \\
\hline & $* * * *$ & Ns & ***** & ***** & $* * * *$ & $* * * *$ & $* * * *$ & $* * * *$ & $* * * *$ & Ns \\
\hline & 7.977 & 0.5983 & 14.21 & -0.1985 & 1.314 & 5.426 & 1.097 & 1.341 & 0.7029 & -0.178 \\
\hline & ***** & $* * * *$ & $* * * *$ & $* * * *$ & ***** & $* * * *$ & $* * * *$ & $* * * *$ & $* * * *$ & ***** \\
\hline & 15.15 & 8.067 & 6.639 & 0.05096 & 1.577 & 7.596 & 6.880 & 2.439 & 1.278 & 7.382 \\
\hline & $* * * * *$ & ***** & $* * * *$ & ***** & ***** & $* * * *$ & $* * * *$ & $* * *$ & ***** & ***** \\
\hline & 28.38 & 7.745 & 21.19 & -0.1851 & 3.099 & 7.590 & 6.769 & -1.063 & 1.451 & 6.751 \\
\hline & $* * * *$ & ***** & $* * * *$ & $\mathrm{Ns}$ & *** & $* * * *$ & $* * * *$ & $*$ & *** & $* * * *$ \\
\hline & -10.03 & -5.873 & -5.540 & -0.01535 & -0.363 & -1.988 & -5.388 & -0.750 & -0.332 & -5.981 \\
\hline & *** & $* *$ & $* * * *$ & $* * * *$ & Ns & Ns & Ns & Ns & Ns & $* *$ \\
\hline & -2.849 & 1.595 & -13.11 & 0.2341 & -0.101 & 0.1818 & 0.3956 & 0.3476 & 0.2422 & 1.579 \\
\hline & $* * * *$ & $*$ & Ns & Ns & $* * * *$ & Ns & Ns & $* * * *$ & **** & Ns \\
\hline & 10.37 & 1.274 & 1.441 & -0.001978 & 1.421 & 0.1756 & 0.2839 & -3.155 & 0.4152 & 0.9481 \\
\hline & $* * * *$ & $* * * *$ & $* * * *$ & $* * * *$ & Ns & $* * * *$ & $* * * *$ & $* * *$ & $* * * *$ & $* * * *$ \\
\hline & 7.176 & 7.468 & -7.572 & 0.2494 & 0.2622 & 2.170 & 5.784 & 1,098 & 0.5751 & 7.560 \\
\hline $\mathrm{CH} \mathrm{v}$ & ***** & ***** & $* * * *$ & Ns & $* * * *$ & $* * * *$ & $* * * *$ & $* * * *$ & $* * * *$ & $* * * *$ \\
\hline Mean Diff & 20.40 & 7.147 & 6.981 & 0.01337 & 1.785 & 2.164 & 5.672 & -2.404 & 0.7481 & 6.929 \\
\hline GH vs MA & $* * * *$ & Ns & $* * * *$ & ***** & $* * * *$ & Ns & & $* * * *$ & & Ns \\
\hline Mean Diff & 13.22 & -0.3216 & 14.55 & -0.2361 & 1.522 & -0.006 & -0.111 & -3.502 & 0.1730 & -0.631 \\
\hline
\end{tabular}

* Weakly significant, $* *$ Moderately significant, $* * *$ Highly significant, $* * * *$ Very highly significant, Ns non-significant F.W Fig weight, F.Wi Fig width, F.L Fig length, Wi/L Fig width /Fig length, O.W Ostiole width, N.L Neck length , N.T Neck thickness, S.L Stalk length, S.T Stalk thickness, P.T Pulp thickness.

This investigation has shown that the number of lobes per leaf (Fig 12) varies between 3 and 5 for $\mathrm{AH}(3.6 \pm 0.9)$, MA (3.66 \pm 0.94$), \mathrm{CH}(3.71 \pm 0.96)$ and $\mathrm{BN}(4.2 \pm 0.98)$ but for $\mathrm{GH}(5.22 \pm 1.38 \mathrm{~mm})$ it is between 3 and 7. The great majority of the studied leaves have three lobes in $\mathrm{AH}, \mathrm{CH}$ and MA in contrast to BN and $\mathrm{GH}$ they have five lobes.

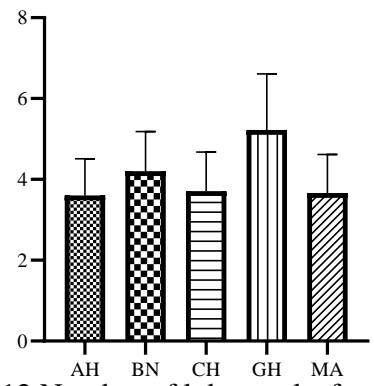

Fig12.Number of lobe per leaf average

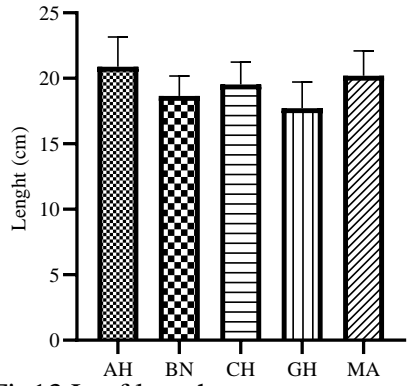

Fig13.Leaf length average 
Moreover, AH $(20.89 \pm 2.26 \mathrm{~cm})$ fig tree has the longest leaves followed by MA, CH, BN and GH $(17.72 \pm 2.009$ $\mathrm{cm}$ ) in that order (Fig13). AH $(18.56 \pm 2.75 \mathrm{~cm})$ and $\mathrm{CH}$ fig trees has the greatest leaf width (Fig14) followed by $\mathrm{GH}, \mathrm{MA}$ and BN $(17.04 \pm 1.46 \mathrm{~cm})$. The average leaf area of AH $\left(392.9 \pm 97.98 \mathrm{~cm}^{2}\right)$ followed by $\mathrm{CH}, \mathrm{MA}, \mathrm{GH}$, and BN $\left(319.7 \pm 51.60 \mathrm{~cm}^{2}\right)$ in that order. These values show that their areas are Medium [250-400 $\left.\mathrm{cm}^{2}\right]$, while the data demonstrate that all of these cultivars have large leaf areas $\left[400-500 \mathrm{~cm}^{2}\right]$, with only AH and $\mathrm{CH}$ having a very large area $\left[>550 \mathrm{~cm}^{2}\right]$ and GH having a tiny area $\left[250 \mathrm{~cm}^{2}\right]$ (Fig 15).

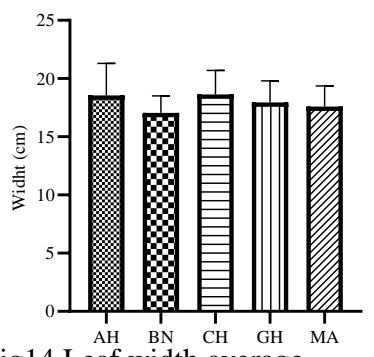

Fig14.Leaf width average

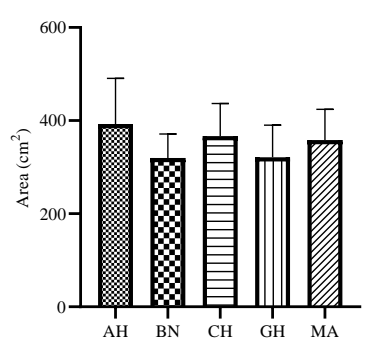

Fig15.Leaf area average

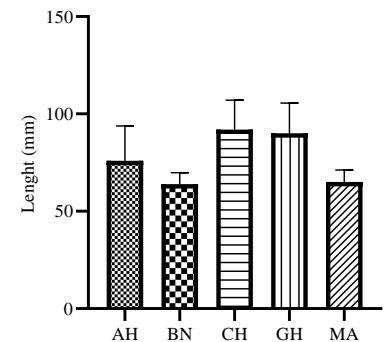

Fig16.Leaf stalk length average

Regarding leaf stalks length $\mathrm{CH}(91.92 \pm 15.11 \mathrm{~mm})$ and $\mathrm{GH}(90.11 \pm 15.42 \mathrm{~mm})$ have a long leaf stalks [> 80 $\mathrm{mm}]$ while AH $(75.93 \pm 17.92 \mathrm{~mm})$; MA $(65.05 \pm 6.152 \mathrm{~mm})$ and $\mathrm{BN}(63.90 \pm 5.858 \mathrm{~mm})$ have a medium leaf stalks $[50-80 \mathrm{~mm}]$ (Fig 16). The highest average for leaf stalk length/leaf length ratio was recorded by $\mathrm{GH}(0.508 \pm 0.072)$, followed by $\mathrm{CH}, \mathrm{AH}, \mathrm{BN}$, and MA (0.322 \pm 0.019$)$ varieties (Fig17).

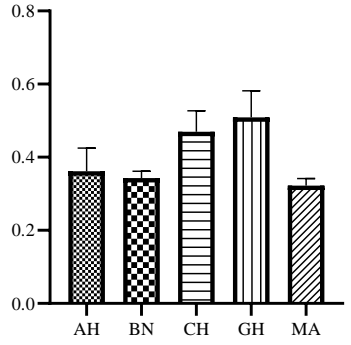

Fig17.Leaf stalk length/leaf length average Fig18.Leaf stalk thickness average

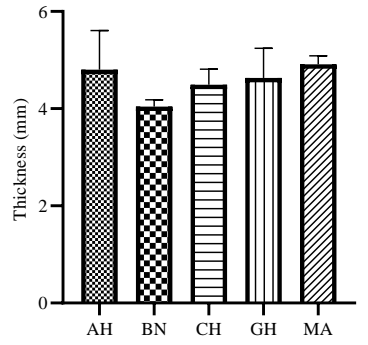

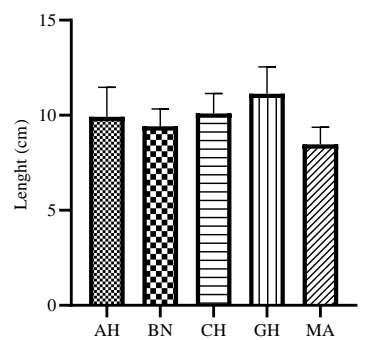

Fig19.Leaf lobe central length average

The leaf stalks length is not proportional to the leaves length. When it comes to leaf stalk thickness, MA $(4.912 \pm 0.177 \mathrm{~mm})$ is the thickest, followed by $\mathrm{AH}, \mathrm{GH}, \mathrm{CH}$, and $\mathrm{BN}(4.043 \pm 0.141 \mathrm{~mm})$ in that order (Fig18). We noticed that the leaf stalks length is not proportional to the leaf stalks thickness.

Concerning the leaf central lobe length (Fig 19), GH $(11.13 \pm 1.415 \mathrm{~cm}$ ) is the longest then $\mathrm{CH}$ followed by AH; $\mathrm{BN}$ and MA $(8.472 \pm 0.896 \mathrm{~cm})$ in that order. According to the results of degree of leaf lobation [= Length of central lobe/ length of leaf] (Fig 20) GH (0.629 \pm 0.055$)$; $\mathrm{CH}(0.519 \pm 0.058)$ and $\mathrm{BN}(0.504 \pm 0.018)$ have a marked lobation [0.51 - 0.75], while AH $(0.47 \pm 0.045)$ and MA $(0.41 \pm 0.016)$ are on average lobation [0.26 $0.50]$. As for the number of leaves per shoot (Fig 21) BN (14.63 \pm 1.55$)$ and MA have the biggest number, then $\mathrm{AH}$ followed by $\mathrm{CH}$ and $\mathrm{GH}(6.467 \pm 1.10)$ at last.

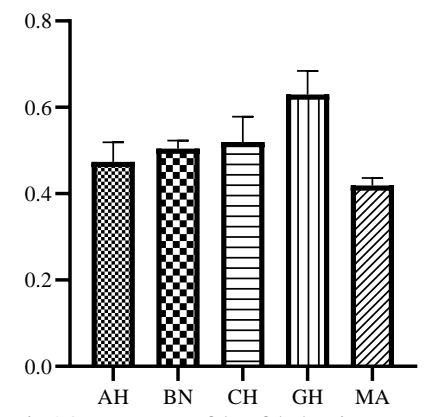

Fig20.Degree of leaf lobation average

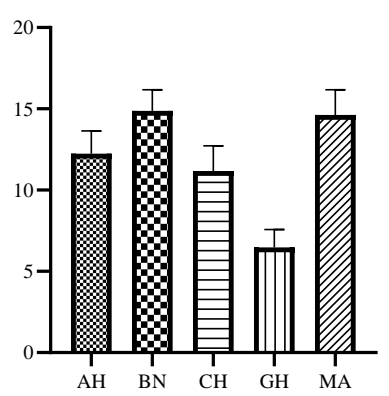

Fig21.Number of leaves per shoot average

Foliar analyzes show that the variability associated with the leaf area, leaf stalk size and the number of leaves per shoot, may be influenced by genetic characteristics. The leaf areas vary according to the varieties [19], this variation is independent of the number of leaves per shoot, of the number of lobes per leaf and their shape. 
Morphological characteristics such as leaf size; number of leaves per shoot and pulp thickness; are important to selector and can be highly distinguishing variables. Nevertheless, differentiating fig tree varieties using their leaves is difficult because they are polymorphic within the same individual, particularly in terms of the number of lobes and the leaf stalk thickness[20].

The results of multiple comparisons of leaf character averages (Table 4) demonstrate a high degree of diversity among genotypes, with some exceptions in the characteristics listed below: Number of lobe regarding $\mathrm{AH} ; \mathrm{CH}$ and MA between them, Leaf length between AH/MA and CH/MA, Leaf width regarding $\mathrm{AH} ; \mathrm{CH}$ and $\mathrm{GH}$ between them also between BN/MA and GH/MA, Leaf area between $\mathrm{AH} / \mathrm{CH}$ and $\mathrm{CH} / \mathrm{MA}$, leaf stalk length/Leaf length between AH/BN and BN/MA, leaf stalk length between BN/MA and CH/GH ,leaf stalk thickness regarding $\mathrm{CH} ; \mathrm{GH}$ and $\mathrm{BN}$ or MA between them also between AH/GH and AH/MA, Lobe central length between $\mathrm{AH} / \mathrm{CH}$, Degree of lobation leaf between BN/CH, Number of leaves per shoot between BN/MA.

Table4. Ordinary one-way ANOVA of leaves characters $(n=150)$ averages

\begin{tabular}{|c|c|c|c|c|c|c|c|c|c|c|}
\hline $\begin{array}{c}\text { Tukey's multiple } \\
\text { comparisons test }\end{array}$ & N.L & $\begin{array}{c}\text { L.L } \\
(\mathrm{cm})\end{array}$ & $\begin{array}{c}\text { L.W } \\
(\mathrm{cm})\end{array}$ & $\begin{array}{c}\text { L.A } \\
\left(\mathrm{cm}^{2}\right)\end{array}$ & LS.L/L.L & $\begin{array}{c}\text { LS.L } \\
(\mathrm{mm})\end{array}$ & $\begin{array}{c}\text { LS.T } \\
(\mathrm{mm})\end{array}$ & $\begin{array}{c}\text { LC.L } \\
(\mathrm{cm})\end{array}$ & $\begin{array}{c}\text { DL.L } \\
(\mathrm{mm})\end{array}$ & $\begin{array}{c}\text { N.L/S } \\
(\mathrm{mm})\end{array}$ \\
\hline AH vs BN & $* *$ & $* * * *$ & $* * * *$ & $* * *$ & Ns & $* * * *$ & $* * * *$ & $*$ & $* * * *$ & $* * * *$ \\
Mean Diff & -0.6000 & 2.225 & 1.515 & 73.21 & 0.01879 & 12.03 & 1.120 & 0.5027 & -0.0302 & -2.633 \\
\hline AH vs CH & Ns & $* * * *$ & Ns & Ns & $* * * *$ & $* * * *$ & $*$ & Ns & $* * * *$ & $*$ \\
Mean Diff & -0.1111 & 1.357 & -0.07667 & 26.38 & -0.1081 & -15.99 & 0.6734 & -0.1829 & -0.0457 & 1.067 \\
\hline AH vs GH & $* * * *$ & $* * * *$ & Ns & $* * * *$ & $* * * *$ & $* * * *$ & Ns & $* * * *$ & $* * * *$ & $* * * *$ \\
Mean Diff & -1.622 & 3.168 & 0.6097 & 71.54 & -0.1473 & -14.17 & 0.5304 & -1.212 & -0.1555 & 5.767 \\
\hline AH vs MA & Ns & Ns & $*$ & $*$ & $* * * *$ & $* * * *$ & Ns & $* * * *$ & $* * * *$ & $* * * *$ \\
Mean Diff & -0.06667 & 0.6842 & 0.9566 & 34.48 & 0.03896 & 10.89 & 0.2516 & 1.445 & 0.05462 & -2.392 \\
\hline BN vs CH & $*$ & $*$ & $* * * *$ & $* * *$ & $* * * *$ & $* * * *$ & Ns & $* *$ & Ns & $* * * *$ \\
Mean Diff & 0.4889 & -0.8678 & -1.592 & -46.82 & -0.1269 & -28.02 & -0.4466 & -0.6856 & -0.0154 & 3.700 \\
\hline BN vs GH & $* * * *$ & $* *$ & $*$ & Ns & $* * * *$ & $* * * *$ & Ns & $* * * *$ & $* * * *$ & $* * * *$ \\
Mean Diff & -1.022 & 0.9428 & -0.9053 & -1.669 & -0.1660 & -26.20 & -0.5896 & -1.715 & -0.1252 & 8.400 \\
\hline BN vs MA & $* *$ & $* * * *$ & Ns & $* *$ & Ns & Ns & $* *$ & $* * * *$ & $* * * *$ & Ns \\
Mean Diff & 0.5333 & -1.541 & -0.5584 & -38.73 & 0.02018 & -1.147 & -0.8684 & 0.9426 & 0.0848 & 0.2417 \\
\hline CH vs GH & $* * * *$ & $* * * *$ & Ns & $* * *$ & $* * * *$ & Ns & Ns & $* * * * *$ & $* * * *$ & $* * * *$ \\
Mean Diff & -1.511 & 1.811 & 0.6863 & 45.15 & -0.03914 & 1.817 & -0.1430 & -1.029 & -0.1098 & 4.700 \\
\hline CH vs MA & Ns & Ns & $* *$ & Ns & $* * * *$ & $* * * *$ & Ns & $* * * *$ & $* * * *$ & $* * * *$ \\
Mean Diff & 0.04444 & -0.6731 & 1.033 & 8.099 & 0.1471 & 26.87 & -0.4219 & 1.628 & 0.1004 & -3.458 \\
\hline GH vs MA & $* * * *$ & $* * * *$ & Ns & $* * *$ & $* * * *$ & $* * * *$ & Ns & $* * * * *$ & $* * * *$ & $* * * *$ \\
Mean Diff & 1.556 & -2.484 & 0.3469 & -37.06 & 0.1862 & 25.06 & -0.2789 & 2.657 & 0.2101 & -8.158 \\
\hline
\end{tabular}

* Weakly significant, ** Moderately significant, *** Highly significant, ****Very highly significant, Ns non-significant N.L Number of lobe, L.L Leaf length, L.W Leaf width,L.A Leaf area , LS.L/L.L Leaf stalk length/Leaf length, LS.L Leaf stalk length, LS.T Leaf stalk thickness, LC.L Lobe central length, DL.L Degree of lobation leaf,N.L/S Number of leaves per shoot.

The tendency to form suckers is low [less than three] for $\mathrm{AH}$; $\mathrm{BN}$; $\mathrm{CH}$ and $\mathrm{MA}$, medium [three to seven] for GH (Fig 22). The harvest period average is medium [21-40 days] for BN and GH; it coincides with that observed in Turkey varieties [21], Long [41-60 days] for AH and MA, Very long [>60 days] for $\mathrm{CH}$ (Fig 23). The beginning of fruit maturation for BN and GH is early [20-31 July], mid-season [1-15 August] for MA, and late [15-31 August] for $\mathrm{AH}$ and $\mathrm{CH}$. The fig sector in eastern Morocco has the major advantages of fruit cultivation, early harvests (extended beginning of maturity from early to late) and great availability of fresh fruits on the market prolonged harvest period from medium to very long, allowing the market for fresh figs to be satisfied for an extended period of time.

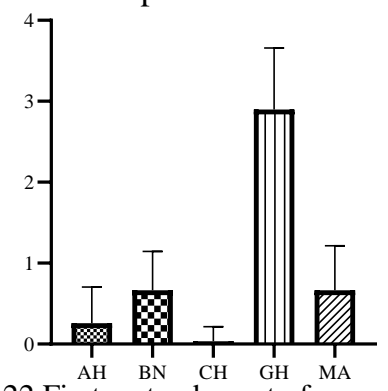

Fig22.Fig tree tendency to form suckers average

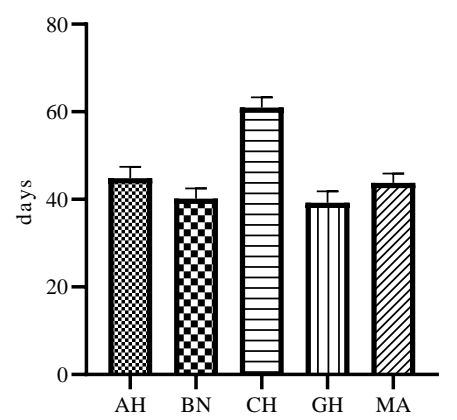

Fig23.Fig tree Harvest period average 
Furthermore, the terminals buds (Fig 24) of $\mathrm{CH}(11.53 \pm 1.93 \mathrm{~mm})$ and $\mathrm{AH}$ are the longest, followed by BN, $\mathrm{GH}$, and MA $(9.172 \pm 0.96 \mathrm{~mm})$.In terms of terminal bud width (Fig 25), AH $(7.196 \pm 0.96 \mathrm{~mm})$ is the largest, followed by $\mathrm{CH}$ and $\mathrm{BN}$, then $\mathrm{GH}$ and $\mathrm{MA}(5.319 \pm 0.56 \mathrm{~mm})$. Regarding to the terminal bud length/width ratio (Fig 26) the biggest one is for $\mathrm{CH}(1.820 \pm 0.20 \mathrm{~mm})$ then $\mathrm{BN}$ and $\mathrm{GH}$ followed by $\mathrm{MA}$ and

$\mathrm{AH}(1.524 \pm 0.15 \mathrm{~mm})$ in that order.

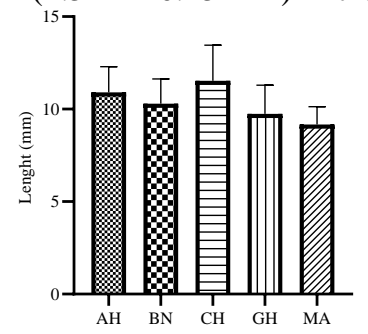

Fig24.Terminal bud length average

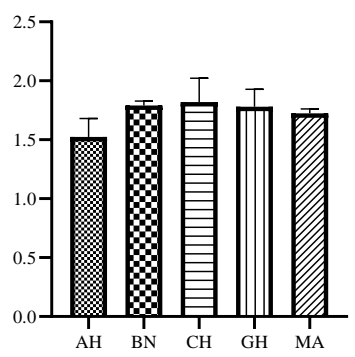

Fig25.Terminal bud width average

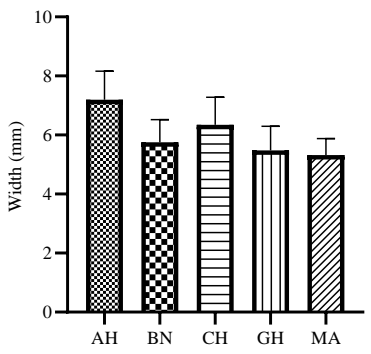

Fig26.Terminal bud length/width average

The terminal bud color is green for $\mathrm{AH}, \mathrm{BN}, \mathrm{CH}$ and MA, Pinkish brown for GH. The dominant terminal bud shape is conical for them at all (Fig27).

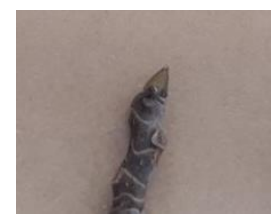

AH terminal bud

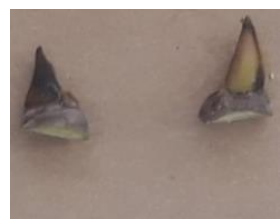

BN terminal bud

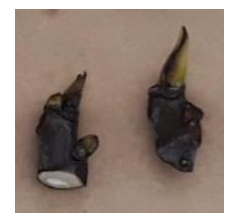

$\mathrm{CH}$ terminal bud

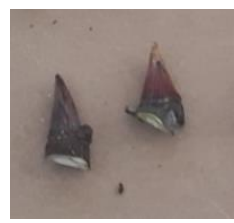

GH terminal bud

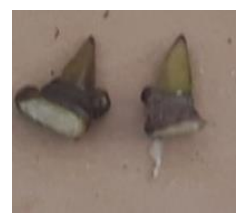

MA terminal bud

Fig27.Terminal bud shape and color of the studied fig cultivars

From the multiple comparisons (table 5), we notice a great variability in tree and terminal bud characters averages with some exceptions in the following variables: Bud terminal length between GH/MA, Bud terminal width between BN/GH and GH/MA, Bud terminal length/Bud terminal width regarding $\mathrm{BN}$; $\mathrm{CH}$ and $\mathrm{GH}$ between them, tendency suckers between $\mathrm{AH} / \mathrm{CH}$ and BN/MA, Harvest period between AH/MA and BN/GH.

Table5. Ordinary one-way ANOVA of tree characters $(n=45)$; terminal bud $(n=150)$; total soluble solids and titratable acidity

\begin{tabular}{|c|c|c|c|c|c|c|c|}
\hline $\begin{array}{c}\text { Tukey's multiple } \\
\text { comparisons test }\end{array}$ & T.S & $\begin{array}{c}\text { H.P } \\
(\text { days })\end{array}$ & $\begin{array}{c}\text { Bt.L } \\
(\mathrm{mm})\end{array}$ & $\begin{array}{c}\text { Bt.W } \\
(\mathrm{mm})\end{array}$ & $\begin{array}{c}\text { L/W } \\
\mathrm{Bt}\end{array}$ & $\begin{array}{c}\text { T.S.S } \\
\%\end{array}$ & $\begin{array}{c}\text { T.A } \\
\%\end{array}$ \\
\hline AH vs BN & $*$ & $* * * *$ & $*$ & $* * * *$ & $* * * *$ & $* * * *$ & $* * * *$ \\
Mean Diff & -0.407 & 4.667 & 0.6146 & 1.443 & -0.266 & 1.575 & -0.028 \\
\hline AH vs CH & Ns & $* * * *$ & $*$ & $* * * *$ & $* * * *$ & $* * * *$ & $* * * *$ \\
Mean Diff & 0.225 & -16.13 & -0.619 & 0.8487 & -0.295 & 4.883 & -0.040 \\
\hline AH vs GH & $* * * *$ & $* * * *$ & $* * * *$ & $* * * *$ & $* * * *$ & Ns & Ns \\
Mean Diff & -2.641 & 5.600 & 1.163 & 1.718 & -0.255 & -0.023 & -0.004 \\
\hline AH vs MA & $*$ & Ns & $* * * *$ & $* * * *$ & $* * * *$ & $* * * *$ & $* *$ \\
Mean Diff & -0.407 & 1.033 & 1.738 & 1.876 & -0.200 & 8.19 & -0.013 \\
\hline BN vs CH & $* * * *$ & $* * * *$ & $* * * *$ & $* * * *$ & Ns & $* * * *$ & $* *$ \\
Mean Diff & 0.633 & -20.80 & -1.234 & -0.594 & -0.028 & 3.327 & -0.011 \\
\hline BN vs GH & $* * * *$ & Ns & Ns & Ns & Ns & $* * * *$ & $* * * *$ \\
Mean Diff & -2.233 & 0.9333 & 0.5483 & 0.2751 & 0.0110 & -1.580 & 0.024 \\
\hline BN vs MA & Ns & $* * * *$ & $* * * *$ & $* *$ & $* *$ & $* * * *$ & $* *$ \\
Mean Diff & 0.000 & -3.633 & 1.124 & 0.4332 & 0.0661 & 6.633 & 0.014 \\
\hline CH vs GH & $* * * *$ & $* * * *$ & $* * * *$ & $* * * *$ & Ns & $* * * *$ & $* * * *$ \\
Mean Diff & -2.867 & 21.73 & 1.783 & 0.8694 & 0.0399 & -4.907 & 0.036 \\
\hline CH vs MA & $* * * *$ & $* * * *$ & $* * * *$ & $* * * *$ & $* * * *$ & $* * * *$ & $* * * *$ \\
Mean Diff & -0.633 & 17,17 & 2.358 & 1.028 & 0.0949 & 3.307 & 0.026 \\
\hline GH vs MA & $* * * *$ & $* * * *$ & Ns & Ns & $*$ & $* * * *$ & $*$ \\
Mean Diff & 2.233 & -4.567 & 0.5754 & 0.1581 & 0.0550 & 8.213 & -0.009 \\
\hline
\end{tabular}

* Weakly significant, $* *$ Moderately significant, $* * *$ Highly significant, ****Very highly significant, Ns non-significant T.S tendency suckers ,H.P harvest period , Bt.L Bud terminal lenght,Bt.W Bud terminal width, L/W Bud terminal length/Bud terminal width, T.S.S Total Soluble Solids, T.A Titratable Acidity 
Regarding to the total soluble solids (Fig 28$) \mathrm{GH}(24.16 \pm 0.04 \%)$ and $\mathrm{AH}(24.13 \pm 0.01 \%)$ have the highest percentages, followed by BN; $\mathrm{CH}$ and MA $(15.94 \pm 0.08 \%)$. As for titratable acidity (Fig 29) CH $(0.272 \pm 0.03$ $\%$ C.A= Citric. Acid $)$ has the highest percentage, followed by BN, MA; GH and AH $(0.231 \pm 0.004 \%$ C.A $)$ in that orders. The chemical fruits characteristics are important in the pomological quality determination and can also be used for varietal discrimination [22]. Fig fruit with a good quality should have a soluble solid content between $13.0 \%$ and $25.1 \%$, and an acidity levels between 0.226 and $0.300 \%$ [23]; these two criteria are met by our cultivars studied. Also significant differences of total soluble solids and titratable acidity averages in figs cultivar are noted except between $\mathrm{AH}$ and $\mathrm{GH}$ for these two traits (table5).

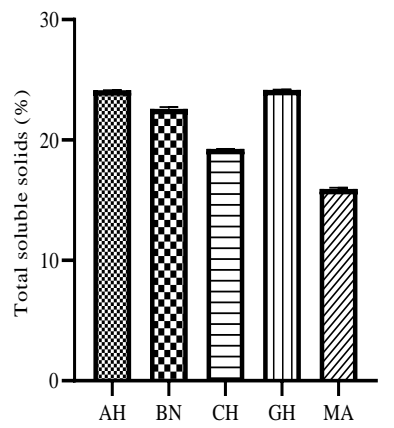

Fig28.Figs total soluble solids average

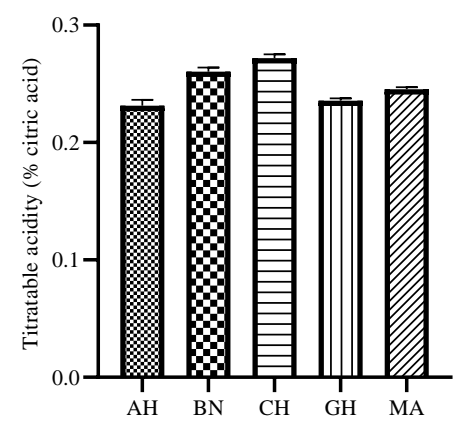

Fig29.Figs titratable acidity average

In order to determine the quality of figs; we use the weighted ranked method of Aksoy, based on nine characteristics which are with their weighting: the weight of the fruit $(\mathrm{g}) 20$; beginning of maturation 20; shape of the fruit (index) 9; neck length $(\mathrm{mm}) 6$; fruit skin cracks 10; ease of peeling 10; ostiole width (mm) 5; total soluble solids (\%) 10 and titratable acidity (\%) 10.The lowest score is obtained by MA (570),followed by $\mathrm{BN}$ (680) then GH (702), while the highest are recorded in particular at $\mathrm{CH}$ (720) and $\mathrm{AH}(738)$, theses scores reflect a very good pomological fig quality in the eastern Morocco (Fig 30). The fig quality is influenced by the genotypic effect, environmental conditions (temperature, humidity, wind...), the maturity stage and cultural maintenance[18].Certain pomological characteristics of apple, such as size and dry matter content, are more affected by the increase of the tree fruit load due to poor tree development. Thus, a weak tree development increases the effect of tree fruit load on fruit quality [24].

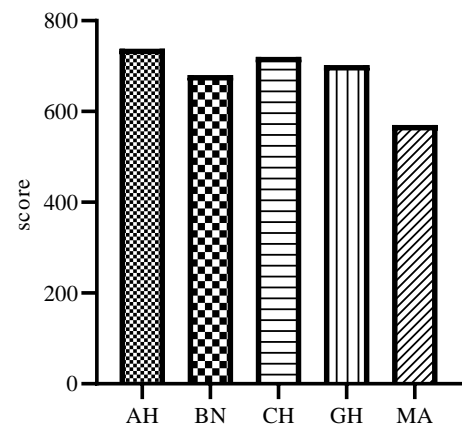

Fig30.Quality of figs by the weighted ranked method of Aksoy

\section{Conclusion}

The overall analysis of our results shows that morphological markers reveal phenotypic variability among the fig tree grown in eastern Morocco. In the studied area, this plant exhibits a wide range of morphological characteristics. Thus, the fig cultivars investigated appear to be well suited to the pedoclimatic conditions, requiring less water and phytosanitary treatment. In order to preserve and maintain the biological diversity of fig trees in this region, this research needs to be completed through the development of illustrated varietal sheets with useful recommendations. (e g A fig cultivars list with useful suggestions developed by nursery workers and arborists to help farmers choose varieties and use. furthermore, from an agricultural point of view, the studied cultivars are popular and recommended by local farmers because of their high fruit yields. Moreover, from an agri-food standpoint, as a summer fruit, these fresh figs produced in this region have an excellent taste, they are sought after and appreciated by consumers, in particular the fruits of the cultivar $\mathrm{AH}, \mathrm{CH}$. Finally, the cultivars $\mathrm{AH}, \mathrm{GH}$ deserve to be candidates for IGP labeling as fresh fruits, not only because of their outstanding quality, but also because of their good pomological parameters and high Aksoy weighted method scores. 
We are grateful to Gharmawne agricultural cooperative. Our thanks are also due at the Regional Directorate of Agriculture (DRA) in Oujda, at the Provincial Directorates of Agriculture (DPA) in Oujda, Berkane, Jerada, Nador and Taourirt for facilitating access for that work. Equal thanks go to the fig farmer producers in the collection sites and Aghbal municipality for the practical assistance and collaboration.

\section{References}

1. M,Pourghayoumi, et al., Phytochemical attributes of some dried fig (Ficus carica L.) fruit cultivars grown in Iran. Agriculturae Conspectus Scientificus, 81(3): p. 161-166 (2016)

2. A.H,Achtak, et al., Traditional agroecosystems as conservatories and incubators of cultivated plant varietal diversity: the case of fig (Ficus carica L.) in Morocco. BMC plant biology,. 10(1): p. 1-12 (2010).

3. Y,Hmimsa., Y. Aumeeruddy-Thomas, and M. Ater, Une forme spontanée de figuier (Ficus carica L.), le nābūt. Diversité de nomenclature, d'usage et de pratiques locales au Nord du Maroc. Revue d'ethnoecologie, (Supplément 1) (2017).

4. B,Khadari, et al., Contrasted genetic diversity and differentiation among Mediterranean populations of Ficus carica L.: a study using mtDNA RFLP. Genetic resources and crop evolution, 52(1): p. 97-109 (2005)

5. D,Zohary, and M. Hopf, Domestication of plants in the Old World: The origin and spread of cultivated plants in West Asia, Europe and the Nile Valley: Oxford University Press (2000).

6. Y,Aumeeruddy-Thomas, and Y. Hmimsa, Fig and olive domestication in the Rif, northern Morocco:Entangled human and tree lives and history, in Hybrid Communities, Routledge. p. 179-196 ( 2018).

7. Y,Hmimsa, Y. Aumeeruddy-Thomas, and M. Ater, Vernacular taxonomy, classification and varietal diversity of fig (Ficus carica L.) among Jbala cultivators in northern Morocco. Human Ecology, 40(2): p. 301-313(2012).

8. A,EL HAJJAM, and A. EZZAHOUANI, Conduite technique et inventaire des variétés locales marocaines de figuier (Ficus carica L.) dans quatre principaux sites de production, provinces de Chefchaouen, El Jadida, Ouezzane, et Taounate. Revue Marocaine des Sciences Agronomiques et Vétérinaires, 6(4): p. 494-504 (2018).

9. L,Hssaini, et al., Characterization of local fig clones (Ficus carica L.) collected in Northern Morocco. Fruits, 74(2): p. 55-64 (2019).

10. I IPGRI, C., Descriptors for fig. International Plant Genetic Resources Institute, Rome, Italy, and International Centre for Advanced Mediterranean Agronomic Studies, Paris, France, 52 (2003).

11. J,GIL,et al., Las higueras canarias y su diversidad: Bases orales y documentales(2011).

12. U,Aksoy,Descriptors for fig (Ficus carica L. and related Ficus sp.). Ege Uni. Faculty of Agriculture. Department of Horticulture, Izmir, Turkey, (1991).

13. H.C.P,Monographie de la région de l'oriental. [p 203](janvier 2021) Available from: https://www.hcp.ma/regionoriental/docs/Monographies/Monographie\%20de\%20la\%20region\%20-\%20Janvier\%202021.pdf.

14. A,Oukabli, S. Bartolini, and R. Viti, Anatomical and morphological study of apple (Malus $\times$ domestica Borkh.) flower buds growing under inadequate winter chilling. The Journal of Horticultural Science and Biotechnology, 78(4): p. 580-585 (2003).

15. A.K,Yadav, Phalsa: A potential new small fruit for Georgia. 1999, ASHS Press: Alexandria, VA, USA. p. 348352(2009).

16. M,Simsek, Evaluation of selected fig genotypes from South east Turkey. African Journal of Biotechnology, 8(19).

17. O,Çalişkan, and A.A. Polat, Morphological diversity among fig (Ficus carica L.) accessions sampled from the Eastern Mediterranean Region of Turkey. Turkish Journal of Agriculture and Forestry, 36(2): p. 179-193(2012).

18. B,Gaaliche,et al, Pomological and biochemical characteristics of fig (Ficus carica L.) cv. Zidi in different agroecological zones of Tunisia. Pak. J. Agri. Sci, 49(4): p. 425-428 (2012).

19. A,Abo-El-Ez,R. Mostafa, and I.F. Badawy, Growth and productivity of three fig (Ficus carica L.) cultivars grown under upper Egypt conditions. Australian Journal of Basic and Applied Sciences, 7(2): p. 709-714(2013).

20. E,Khanfir, Identification of genetic diversity of Ficus carica: Morphological and molecular characterization of varieties from Kerkennah. Editions Universitaires Européennes. Saarbrücken, Allemagne, , 106 p(2015).

21. O,Çalişkan,and A.A. Polat, Fruit characteristics of fig cultivars and genotypes grown in Turkey. Scientia horticulturae, 115(4): p. 360-367(2008).

22. M.B,Miklavcic , B.B., Valencic V., Sugars and Organic Acids Content in Fig Crops, 90-100 pp 2006 and 2007: In The Common Fig (Ficus carica L.) in Istria.Morphological, Molecular and Some Chemical Characteristics. . University of Primorska, Science and Research Centre Koper, Publishing House Annales. Project RGFI -Revitalization of Fig Cultivation in Istria, 104 p(2008).

23. U,Aksoy, et al., Ege Bölgesi koşullarına uygun sofralık incir çeşit seleksiyonu. Türkiye I. Ulusal Bahçe Bitkileri Kongresi, 1: p. 545-548(1992).

24. I,Travers, Influence des conditions pédoclimatiques du terroir sur le comportement du pommier et la composition des pommes à cidre dans le Pays d'Auge, Caen(2004). 